\title{
Antibacterial Resistance Patterns of WHO List of Essential Antibiotics Adopted by Mozambique
}

Filipe António Mahaluça ${ }^{1,2^{*}}$, Sabiha Essack ${ }^{3}$ and Jahit Sacarlal

${ }^{1}$ Higher Institute of Health Sciences (ISCISA), Mozambique

${ }^{2}$ Higher Institute of Accounting and Audit of Mozambique (ISCAM), Mozambique

${ }^{3}$ University of KwaZulu-Natal, South Africa

${ }^{4}$ Faculty of Medicine-Eduardo Mondlane University, Mozambique

"Corresponding author: Filipe António Mahaluça, Higher Institute of Health Sciences (ISCISA), Mozambique, Tel: +21496083 and Higher Institute of Accounting and Audit of Mozambique (ISCAM), Mozambique, Tel: +258-848407234; E-mail: mahaluca@gmail.com

Received date: October 06, 2018; Accepted date: January 29, 2019; Published date: February 05, 2019

Copyright: (C2019 Mahaluça FA, et al. This is an open-access article distributed under the terms of the Creative Commons Attribution License, which permits unrestricted use, distribution, and reproduction in any medium, provided the original author and source are credited.

\section{Abstract}

Background: Combating antibiotic resistance is a high priority for the World Health Organization (WHO). In order to optimize the use of antimicrobials and ensure sustainable investment in the fight against antimicrobial resistance, the WHO has updated the $19^{\text {th }}$ List of Essential Medicines (EML) with new recommendations on antibiotic use by 2017. Since the launch of the first Model of the WHO EML in 1977, many countries adopted the concept of essential medicines and developed their own lists. Mozambique published its first edition in May 2017. To our knowledge, this study is the first to analyzing the antibacterial resistance pattern of the National List of Essential Medicines (EMNL) against bacteria isolated from patients admitted to the Intensive Care Unit (ICU) of the Central Hospital of Maputo (HCM) in 2017.
\end{abstract}

Methods: This was a cross-sectional, epidemiological, quantitative approach, with a retrospective analysis of secondary data, performed at the ICUs in Maputo Central Hospital.

Results: The mean resistance was $62.4 \%, 63.2 \%$ in the ICU-Pediatrics and $60.2 \%$ in the ICU-Adults. In ICUPediatric, the beta-lactams had a resistance of $69.3 \%$, being higher in Gram-positive (75.8\%) and Enterobacteriaceae $(74.2 \%)$. In this class of antibiotics, the penicillins and cephalosporins presented high resistance rates with $80.6 \%$ and $78.6 \%$, respectively; Carbapenems showed good antibiotic activity with a sensitivity of $73.6 \%$. In ICU-Adults, the penicillins presented a good antibiotic activity against the isolated bacteria, with more prominence the cloxacillin with resistance ratio of $4.8 \%$; in this sector, cephalosporins $(70.0 \%)$, quinolones $(81.8 \%)$, aminoglycosides $(69.9 \%)$ and macrolides $(69.6 \%)$ were the classes of antibiotics with high resistance rates.

Conclusion: There is a need for EMNL to be updated with the introduction of new drugs considered as last resort options and used only under the most severe circumstances when all alternatives failed.

Keywords: Bacteria; Antibacterial resistance; List of essential antibiotics; Mozambique

\section{Introduction}

Antibiotic resistance is rising to dangerously high levels in all parts of the world. New mechanisms of resistance are emerging and spreading globally, threatening the human capacity to treat common infectious diseases [1]. According to Centers for Disease Control and Prevention (CDC) (2013) [2], without urgent action against antibiotic resistance, mankind is moving into a post-antibiotic era in which common infections and minor injuries can once again be lethal. Given the ease and frequency with which people travel today, resistance to antibiotics is a global problem, requiring the efforts of all nations and many sectors [3].

Combating antibiotic resistance is a high priority for the World Health Organization (WHO). A global action plan on antimicrobial resistance, including antibiotic resistance, was endorsed by the World Health Assembly in May 2015 to ensure the prevention and treatment of infectious diseases with safe and effective medicines [4]. In order to optimize the use of antimicrobials and ensure sustainable investment in the fight against antimicrobial resistance, the WHO updated the $19^{\text {th }}$ List of Essential Medicines (EML) with new recommendations on the use of antibiotics for 2017 [3].

Since the launch of the first WHO Model of EML in 1977, many countries have adopted the concept of essential medicines and developed their own lists, with Mozambique being issued its first edition in May 2017 to ensure that antibiotics are available when needed and that certain antibiotics are prescribed for the right infections [5]. The goal is to improve treatment outcomes, reduce the development of drug-resistant bacteria, and preserve the effectiveness of the antibiotics of last resort, which are needed when all others fail [6].

Considering the above, this study aims to analyze the antibacterial resistance pattern of the National List of Essential Medicines (EMNL) against bacteria isolated from patients admitted to the Intensive Care Unit (ICU) of the Central Hospital of Maputo (HCM) in the year 2017. 


\section{Materials and Methods}

This was a retrospective, descriptive cross-sectional, epidemiological, quantitative study of data obtained from the HCM Microbiology Laboratory. The study was carried out in the Pediatrics ICU, Medicine ICU and Surgical ICU at HCM from January to December 2017, with the data from latter consolidated. HCM is a quaternary public and teaching hospital with about 1463 beds, provides 4 Intensive Care Services: the Emergency ICU with 16 beds, the Medicine ICU with 6 beds, the Pediatrics ICU with 16 beds and the Surgical ICU with 12 beds. During the study period, 1913 patients of all ages and both sexes were admitted to HCM ICUs, including 1129 in the Pediatrics ICU, 355 in the Medicine ICU and 429 in the Surgical ICU [7].

Data on the profile of etiological agents was extracted from the WHONET electronic database of the HCM Microbiology Laboratory which was set up at the end of October 2009 in order to monitor antimicrobial resistance in bacteria isolated from routine clinical samples. The database contains information on the specimens taken, patient details, growth or non-growth of infectious agents, the bacteria isolated, antibiotic sensitivity, as well as data from the patient justifying examination [8].

A descriptive statistical analysis was performed using graphs and frequency tables to understand the behavior of the variables under study. Data analysis was done with the Statistical Package for Social Sciences (SPSS) version 20 and BioEst version 5.2. The Z-test or Standardized Score was used for the comparison of proportions and the P-value of less than 0.05 was considered significant. Before conducting data analysis, a request for authorization of the research was submitted to the HCM Scientific and Pedagogical Department under reference number 321/024/DCIEFHCM/18. After authorization of the research request, the project was submitted to the ISCISA Institutional Health Bioethics Committee and approved under reference number TFCMCSFM05/18. The study complied with the 2013 Helsinki Declaration on health research standards. For the antibiotic resistance standards of the isolated etiological agents, the categories of sensitive (S), Intermediate (I) and Resistant (R) were considered by obeying the inhibition halo diameters based on the standardization proposed by the Clinical and Laboratory Standards Institute [9].

\section{Results}

According to the data in Tables 1 and 2, 131 patients with bacteriological infections were identified in the study period, $74.8 \%$ of which were in pediatric patients and $25.2 \%$ were adults. The majority of the patients were males with a percentage of $52.7 \%$. For the analysis of age, Pediatrics ICU patients were divided into: infants (1 month to 1 year), pre-school (2 to 5 years), schoolchildren (6 to 10 years) and adolescents (11 to 16 years). According to Table 1, of the 98 patients from the Pediatrics ICU, $51 \%$ are infants, $31.6 \%$ are preschool, $10.2 \%$ are school children and $7.2 \%$ are adolescents. Analyzing the individual age groups, we observed the predominance of males among infants, pre-school and school children. In adolescents the majority were female. The mean age was 3.1 years $(3.1 \pm 0.7)$ and median 1.8 years. Most patients were 2 years old, with the oldest patient being 15 years old and the youngest 1 month old, with no significant difference between the sexes. According to Table 2, of the 33 patients from the ICU-Adults, the majority are male (57.6\%). The mean age is 42.7 years and median age is 42 years. Most patients are 69 years old of age, having the oldest patient 69 years, and the younger 16 years old. The Male patients have a mean age of 48.8 years and female patients 36.1 years, and this difference is significant $(\mathrm{p}=0.0145)$.

\begin{tabular}{|c|c|c|c|c|c|}
\hline \multirow[b]{2}{*}{ Age group } & \multicolumn{2}{|l|}{ Gender } & $\underset{(\%)}{\operatorname{Sum}} \mathrm{n}$ & \multirow[b]{2}{*}{$z$} & \multirow[b]{2}{*}{$\begin{array}{l}\text { P- } \\
\text { Value }\end{array}$} \\
\hline & $\begin{array}{l}\text { Masculine } n \\
(\%)\end{array}$ & $\begin{array}{l}\text { Feminine } \quad n \\
(\%)\end{array}$ & & & \\
\hline Pediatrics & $50(51.0)$ & $48(49.0)$ & 98 (74.8) & - & - \\
\hline Infants & $26(51.0)$ & $23(48.9)$ & $49(50.0)$ & 0.2022 & 0.8398 \\
\hline Preschool & $18(35.3)$ & $13(27.7)$ & $31(31.6)$ & 0.8119 & 0.4168 \\
\hline School & $3(5.9)$ & $7(14.9)$ & $10(10.2)$ & 1.4723 & 0.1409 \\
\hline Adolescents & $4(7.8)$ & $4(8.5)$ & $8(8.2)$ & 0.1206 & 0.904 \\
\hline Sum & $51(52.0)$ & $47(48.0)$ & $98(74.8)$ & - & \\
\hline
\end{tabular}

Table 1: Distribution of patients by sex and age group (pediatrics ICU).

\begin{tabular}{|c|c|c|c|c|c|c|}
\hline \multirow[b]{2}{*}{ Gender } & \multicolumn{6}{|l|}{ Age } \\
\hline & N (\%) & Mean & $\begin{array}{l}\text { S } \\
\text { Deviation }\end{array}$ & $\mathbf{I C}_{95 \%}$ & T-student & $\begin{array}{l}\text { P- } \\
\text { Value }\end{array}$ \\
\hline Feminine & $\begin{array}{l}14 \\
(42.4)\end{array}$ & 36.1 & 13 & $\begin{array}{l}(36.1 \quad \pm \\
7.3)\end{array}$ & & \\
\hline Masculine & $\begin{array}{l}19 \\
(57.6)\end{array}$ & 48.8 & 14.3 & $\begin{array}{ll}(48.8 & \pm \\
7.1) & \end{array}$ & & \\
\hline Sum & $\begin{array}{l}33 \\
(25.2)\end{array}$ & 42.7 & 15.04 & $\begin{array}{ll}(42.7 & \pm \\
5.2) & \end{array}$ & 2.5922 & 0.0145 \\
\hline
\end{tabular}

Table 2: Distribution of patients by sex and age group (Adults ICU).

According to the data in Table 3,179 cultures were identified positive to bacteria, being most isolated from the Gram-negative ones with percentage of $69.3 \%$ compared to $30.7 \%$ of Gram-positive. Among Gram-negative bacteria, Enterobacteriaceae family bacteria were more prevalent with 41.9\%. In the Pediatrics ICU, 127 (70.9\%) cultures were positive for bacteria, 37.8\% Enterobacteriaceae, 32.3\% Non-Fermenting Gram-Negative Bacilli (NFGNB) and 29.9\% GramPositive bacteria. In adults, of the $52(29.1 \%)$ isolated cultures, $51.69 \%$ were from the Enterobacteriaceae family, $32.7 \%$ Gram-positive bacteria and $13.4 \%$ NFGNB.

\begin{tabular}{|l|l|l|l|l|}
\hline \multicolumn{3}{|c|}{ Gram Staining } \\
\hline \multirow{2}{*}{ ICU type } & \multirow{2}{*}{ Positives } & Entegatives & Sum \\
\cline { 3 - 6 } & $\mathbf{n}(\%)$ & $\mathbf{n}(\%)$ & $\mathbf{n}(\%)$ & $\mathbf{n}(\%)$ \\
\hline Pediatric & $38(29.9)$ & $48(37.8)$ & $41(32.3)$ & $127(70.9)$ \\
\hline Adults & $17(32.7)$ & $27(51.9)$ & $8(13.4)$ & $52(29.1)$ \\
\hline Sum & $55(30.7)$ & $75(41.9)$ & $49(27.4)$ & $179(100.0)$ \\
\hline
\end{tabular}

Table 3: Distribution of infectious bacteria for gram staining and ICU type. 
According to Chart 1 , the rate of infection in the Pediatrics ICU was $11.3 \%$ in a ratio of $1.3(127 / 98)$ infection per patient, with May, November, January and December registering high rates with $17.2 \%$, $16.7 \%, 14.4 \%$ and $13.9 \%$, respectively. The months of October, March, June and April also registered rates above the average of 12.9\%, 12.3\%, $11.9 \%$ and $11.6 \%$ respectively. In this sector, the lowest rates were recorded in February (5.5\%), August (5.8\%), July (6.9\%) and September (8.2\%).

In Adults ICU, the overall infection rate was $13.7 \%$ at a ratio of 1.6 (49/30) infection per patient, with January (31.6\%), May (29.5\%), March (26.1\%), August (21.9\%) and September (17.6\%) registered high rates. The months of December (2.4\%), February (4.8\%), November (5\%), July (7.1\%) and October (9.1\%) had below average infection rates. The month of April did not register any case of infection in the Adults ICU.

Thus, the mean infection rate in HCM ICUs was $11.9 \%$ in 2017 , with May (19.7\%), January (17.2\%), June (15.7\%), March (15.6\%), November 13.4\%) recorded above-average rates (Figure 1).

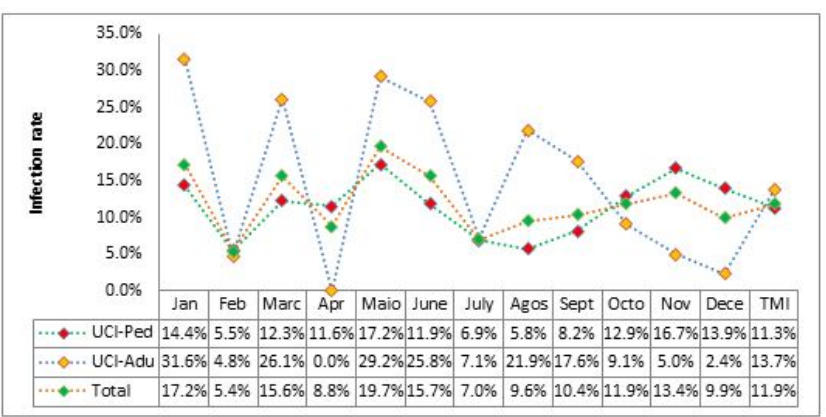

Figure 1: Monthly and general distribution of the infection rate by type of ICU.
Table 4 shows the results of the resistance to EMNL of bacteria isolated in the Pediatrics ICU.

The beta-lactams had a resistance of $69.3 \%$, being higher in Grampositive (75.8\%) and Enterobacteriaceae (74.2\%). In this class of antibiotics, the penicillins and cephalosporins presented high resistance rates with $80.6 \%$ and $78.6 \%$, respectively. Carbapenems showed good antibiotic activity with a sensitivity of $73.6 \%$.

Gentamicin presented a mean resistance of $70.6 \%$, with the lowest in Gram-positive bacteria isolates with a percentage of $52.6 \%$, NFGNB (64\%) and Enterobacteriaceae (91.7\%)

Ciprofloxacin was the most tested antibiotic, presenting a mean resistance of $63.5 \%$. This antibiotic had the highest resistance in Enterobacteriaceae with a percentage of $61.1 \%$.

Vancomycin had a resistance of $66.7 \%$ and was only tested on Gram-positive bacteria.

In macrolides, azithromycin did not inhibit growth of any bacterial strain and erythromycin showed a resistance of $59.3 \%$.

Clindamycin was only tested on Gram-positive bacteria, presenting a resistance of $34.5 \%$.

Co-trimoxazole showed an average resistance of $85.1 \%, 91.7 \%$ in Enterobacteriaceae, $87.5 \%$ in NFGNB and $73.3 \%$ in Gram-positive bacteria.

Chloramphenicol was the second antibiotic most tested in bacteria isolated in the Pediatrics ICU, presenting an average resistance of 44.3\%. This antibiotic showed good antibiotic activity against Grampositive bacteria and Enterobocteriaceae with sensitivity of $83.7 \%$ and $65.4 \%$, respectively.

The antibiotic resistance of the EMNL of bacteria isolated in the Pediatrics ICU was $63.2 \%$, being Enterobacteriaceae (70.2\%), NFGNB (62.1\%) and Gram-positive bacteria (56\%).

\begin{tabular}{|c|c|c|c|c|c|c|c|c|}
\hline \multirow{3}{*}{$\begin{array}{l}\text { EMNL } \\
\text { Antibiotics Tested }\end{array}$} & \multicolumn{8}{|c|}{ Family of bacteria } \\
\hline & \multicolumn{2}{|c|}{ Bacteria Gram + } & \multicolumn{2}{|c|}{ Enterobacteriaceae } & \multicolumn{2}{|c|}{ NFGNB } & \multicolumn{2}{|c|}{ Sum } \\
\hline & $\mathbf{N}$ & n (Res\%) & $\mathbf{N}$ & n (Res\%) & $\mathbf{N}$ & n (Res\%) & $\mathbf{N}$ & n (Res\%) \\
\hline Beta-lactams & 62 & $47(75.8)$ & 124 & $92(74.2)$ & 88 & $51(58.0)$ & 274 & $190(69.3)$ \\
\hline Penicillin's & 42 & $34(81.0)$ & 38 & $32(84.2)$ & 13 & $9(69.2)$ & 93 & $75(80.6)$ \\
\hline Amoxicillinn & 2 & $2(100.0)$ & 10 & $8(80.0)$ & 2 & $2(100.0)$ & 14 & $12(85.7)$ \\
\hline Ampicillin & 10 & $8(80.0)$ & 28 & $24(85.7)$ & 11 & $7(63.6)$ & 49 & $39(79.6)$ \\
\hline Cloxacillin & 1 & $1(100.0)$ & & & & & 1 & $1(100.0)$ \\
\hline Penicillin G & 29 & $23(79.3)$ & & & & & 29 & $23(79.6)$ \\
\hline Cephalosporin's & 15 & $11(73.3)$ & 66 & $55(83.3)$ & 47 & $35(74.5)$ & 128 & 101 (78.9) \\
\hline Cephalexin & 1 & $1(100.0)$ & 1 & $1(100.0)$ & & & 2 & $2(100.0)$ \\
\hline Cefazolin & 1 & $1(100.0)$ & 2 & $2(100.0)$ & 1 & $0(0.0)$ & 4 & $3(75.0)$ \\
\hline Ceftriaxone & 6 & $3(50.0)$ & 22 & $19(86.4)$ & 23 & $20(87.0)$ & 51 & $42(82.4)$ \\
\hline Cefotaxime & 4 & $3(75.0)$ & 15 & $14(93.3)$ & 6 & $5(83.3)$ & 25 & $22(88.0)$ \\
\hline
\end{tabular}


Citation: Mahaluça FA, Essack S, Sacarlal J (2019) Antibacterial Resistance Patterns of WHO List of Essential Antibiotics Adopted by

\begin{tabular}{|c|c|c|c|c|c|c|c|c|}
\hline Ceftazidime & 3 & $3(100.0)$ & 26 & $19(73.1)$ & 17 & $10(58.8)$ & 46 & $32(69.6)$ \\
\hline Carbapenem & 5 & $2(40.0)$ & 20 & $5(25.0)$ & 28 & $7(25.0)$ & 53 & $14(26.4)$ \\
\hline Imipenem & 5 & $2(40.0)$ & 20 & $5(25.0)$ & 28 & $7(25.0)$ & 53 & $14(26.4)$ \\
\hline Aminoglycosides & 19 & $10(52.6)$ & 24 & $22(91.7)$ & 25 & $16(64.0)$ & 68 & $48(70.6)$ \\
\hline Gentamicin & 19 & $10(52.6)$ & 24 & $22(91.7)$ & 25 & $16(64.0)$ & 68 & $48(70.6)$ \\
\hline Quinolones & 23 & $11(47.8)$ & 36 & $22(61.1)$ & 36 & $21(58.3)$ & 85 & $54(63.5)$ \\
\hline Ciprofloxacin & 23 & $11(47.8)$ & 36 & $22(61.1)$ & 36 & $21(58.3)$ & 85 & $54(63.5)$ \\
\hline Glycoptides & 6 & $2(33.3)$ & & & & & 6 & $2(33.3)$ \\
\hline Vancomycin & 6 & $2(33.3)$ & & & & & 6 & $2(33.3)$ \\
\hline Macrolides & 28 & $17(60.7)$ & 1 & $1(100.0)$ & & & 29 & $18(62.1)$ \\
\hline Azithromycin & 1 & $1(100.0)$ & 1 & $1(100.0)$ & & & 2 & $2(100.0)$ \\
\hline Erythromycin & 27 & $16(59.3)$ & & & & & 27 & $16(59.3)$ \\
\hline Lincosamides & 29 & $10(34.5)$ & & & & & 29 & $10(34.5)$ \\
\hline Clindamycin & 29 & $10(34.5)$ & & & & & 29 & $10(34.5)$ \\
\hline Sulfonamides & 15 & $11(73.3)$ & 24 & $22(91.7)$ & 8 & $7(87.5)$ & 47 & $40(85.1)$ \\
\hline Co-trimoxazol & 15 & $11(73.3)$ & 24 & $22(91.7)$ & 8 & $7(87.5)$ & 47 & $40(85.1)$ \\
\hline Others & 25 & $8(32.0)$ & 33 & $11(33.3)$ & 17 & $13(76.5)$ & 75 & $32(42.7)$ \\
\hline Chloramphenicol & 19 & $5(26.3)$ & 26 & $9(34.6)$ & 16 & $13(81.3)$ & 61 & $27(44.3)$ \\
\hline Nitrofurantoin & 6 & $3(50.0)$ & 7 & $2(28.6)$ & 1 & $0(0.0)$ & 14 & $5(35.7)$ \\
\hline Sum & 207 & $116(56.0)$ & 242 & $170(70.2)$ & 174 & $108(62.1)$ & 623 & 394 (63.2) \\
\hline
\end{tabular}

Table 4: Pattern of antibiotic resistance of EMNL against bacteria isolated in the pediatrics ICU.

According to Table 5, the bacteria isolated in Adults ICU patients presented resistance to penicillins of $38.3 \%$. In this class of antibiotics, amoxicillin did not inhibit growth of any single bacterial strain. Penicillin G had a resistance of $71.4 \%$ and was only tested on Grampositive bacteria. Cloxacillin was the most tested antibiotic in the class of penicillins and showed good antibiotic activity with a mean sensitivity of $95.2 \%$.

Cephalosporins had a mean resistance of $70 \%$ and did not inhibit growth of any single NFGNB strain. In this class of antibiotics, cephalosporins of the $3^{\text {rd }}$ generation presented high resistance indexes, being cefotaxime $(78.9 \%)$, ceftazidime $(72.7 \%)$ and ceftriaxone $(60 \%)$.
Imipinem was more tested in Enterobacteriaceae, presenting a resistance of $57.1 \%$.

Gentamicin was more resistant to Gram-negative bacteria, with Enterobacteriaceae (83.3\%) and NFGNB (75\%).

Vancomycin, erythromycin and clindamycin were tested in Gram positive bacteria, and presented resistance with $0.0 \%, 66.47 \%$ and $42.9 \%$, respectively.

Chloramphenicol did not inhibit growth of any strain isolated from Enterobacteriaceae and in Gram-positive bacteria and NFGNB the resistance was $55.63 \%$ and $50 \%$ respectively.

\begin{tabular}{|c|c|c|c|c|c|c|c|c|}
\hline \multirow{3}{*}{$\begin{array}{l}\text { EMNL } \\
\text { Antibiotics Tested }\end{array}$} & \multicolumn{8}{|c|}{ Family of bacteria } \\
\hline & \multicolumn{2}{|c|}{ Bacteria Gram+ } & \multicolumn{2}{|c|}{ Enterobacteriaceae } & \multicolumn{2}{|c|}{ NFGNB } & \multicolumn{2}{|c|}{ Sum } \\
\hline & $\mathbf{N}$ & n (\%) & N & n (\%) & $\mathbf{N}$ & n (\%) & $\mathbf{N}$ & n (\%) \\
\hline Beta-lactam & 22 & $13(59.1)$ & 92 & 49 (53.3) & 21 & $14(66.7)$ & 135 & $76(56.3)$ \\
\hline Penicillin's & 10 & $6(60.0)$ & 30 & $11(36.7)$ & 7 & $1(14.3)$ & 47 & $18(38.3)$ \\
\hline Amoxicillinn & & & 1 & $1(100.0)$ & & & 1 & $1(100.0)$ \\
\hline
\end{tabular}


Citation: Mahaluça FA, Essack S, Sacarlal J (2019) Antibacterial Resistance Patterns of WHO List of Essential Antibiotics Adopted by

\begin{tabular}{|c|c|c|c|c|c|c|c|c|}
\hline Ampicillin & 3 & $1(33.3)$ & 12 & $9(75.0)$ & 3 & $1(33.3)$ & 18 & $11(61.1)$ \\
\hline Cloxacillin & & & 17 & $1(5.9 \%)$ & 4 & 0 & 21 & $1(4.8)$ \\
\hline Penicillin G & 7 & $5(71.4)$ & & & & & 7 & $5(71.4)$ \\
\hline Cephalosporin's & 9 & $6(66.7)$ & 48 & $30(62.5)$ & 13 & $13(100.0)$ & 70 & $49(70.0)$ \\
\hline Cephalexin & & & 4 & $2(40.0)$ & 1 & $1(100.0)$ & 5 & $3(60.0)$ \\
\hline Cefazolin & & & 17 & $10(58.8)$ & 2 & $2(100.0)$ & 19 & $12(63.2)$ \\
\hline Ceftriaxone & 4 & $2(50.0)$ & 1 & $1(100.0)$ & & & 5 & $3(60.0)$ \\
\hline Cefotaxime & 1 & $1(100.0)$ & 13 & $9(69.2)$ & 5 & $5(100.0)$ & 19 & 15 (78.9) \\
\hline Ceftazidime & 4 & $3(75.0)$ & 13 & $8(61.5)$ & 5 & $5(100.0)$ & 22 & $16(72.7)$ \\
\hline Carbapenem & 2 & $1(33.3)$ & 14 & $8(57.1)$ & 1 & $0(0.0)$ & 17 & $9(52.9)$ \\
\hline Imipenem & 2 & $1(50.0)$ & 14 & $8(57.1)$ & 1 & $0(0.0)$ & 17 & $9(52.9)$ \\
\hline Aminoglycosides & 7 & $3(50.0)$ & 12 & $10(83.3)$ & 4 & $3(75.0)$ & 23 & $16(69.6)$ \\
\hline Gentamicin & 7 & $3(50.0)$ & 12 & $10(83.3)$ & 4 & $3(75.0)$ & 23 & $16(69.6)$ \\
\hline Quinolones & 5 & $3(60.0)$ & 5 & $5(100.0)$ & 1 & $1(100.0)$ & 11 & $9(81.8)$ \\
\hline Ciprofloxacin & 5 & $3(60.0)$ & 5 & $5(100.0)$ & 1 & $1(100.0)$ & 11 & $9(81.8)$ \\
\hline Glycoptides & 4 & $0(0.0)$ & & & & & 4 & $0(0.0)$ \\
\hline Vancomycin & 4 & $0(0.0)$ & & & & & 4 & $0(0.0)$ \\
\hline Macrolides & 12 & $8(66.7)$ & & & & & 12 & $8(66.7)$ \\
\hline Erythromycin & 12 & $8(66.7)$ & & & & & 12 & $8(66.7)$ \\
\hline Lincosamides & 7 & $3(42.9)$ & & & & & 7 & $3(42.9)$ \\
\hline Clindamycin & 7 & $3(42.9)$ & & & & & 7 & $3(42.9)$ \\
\hline Tetracycline's & & & 1 & $1(100.0)$ & 1 & $1(100.0)$ & 2 & $2(100.0)$ \\
\hline Doxycycline & & & 1 & $1(100.0)$ & 1 & $1(100.0)$ & 2 & $2(100.0)$ \\
\hline Sulfonamides & 2 & $2(100.0)$ & 2 & $0(0.0)$ & & & 4 & $2(50.0)$ \\
\hline Co-trimoxazol & 2 & $2(100.0)$ & 2 & $0(0.0)$ & & & 4 & $2(50.0)$ \\
\hline Other & 10 & $5(50.0)$ & 11 & $11(100.0)$ & 2 & $1(50.0)$ & 23 & $17(73.9)$ \\
\hline Chloramphenicol & 9 & $5(55.6)$ & 10 & $10(100.0)$ & 2 & $1(50.0)$ & 21 & $16(76.2)$ \\
\hline Nitrofurantoin & 1 & $0(0.0)$ & 1 & $1(100.0)$ & & & 2 & $1(50.0)$ \\
\hline Sum & 69 & 37 (53.6) & 123 & 76 (61.9) & 29 & 20 (68.9) & 221 & $133(60.2)$ \\
\hline
\end{tabular}

Table 5: Antibiotic resistance pattern of MNL against bacteria isolated in adults ICU.

\section{Discussion}

In the present study, the mean resistance of bacteria isolated from penicillins was $66.4 \%$, amoxicillin (86.7\%), penicillin G $(77.7 \%)$, ampicillin $(74.6 \%)$ and cloxacillin $9.1 \%$. These results approximate the findings of Monteiro et al. [8] in patients hospitalized in HCM, where it had an average resistance of $88.8 \%$ to amoxicillin and $90.6 \%$ to ampicillin. Cloxacillin has shown good antibiotic activity against the etiological agents, as was also verified by Nyasulu et al. [10] in a study conducted in tertiary hospitals in South Africa witch found an average resistance of $15.4 \%$ to this antibiotic. Regarding resistance to penicillin G, Van der Meeren et al. [11] a study performed at the Hospital Central da Beira (HCB) found a percentage of $94.9 \%$, which is slightly higher when compared to the findings in this study.

The mean resistance to cephalosporins was $76.3 \%$, with cefotaxime (84.1\%), ceftriaxone $(80.4 \%)$, cephalexin $(71.4 \%)$, ceftazidime $(70.6 \%)$ and cefazolin (69.6\%). Monteiro et al. [8] found an average resistance 
of $37 \%$ to cefotaxime and $40.7 \%$ to ceftazidime, very low percentages when compared with the findings in this study. The results of the present study corroborate with the findings by Van der Meeren et al. [11], where it found an average resistance of $87.1 \%$ to cefazolin and $77.4 \%$ to cefotaxime and ceftazidime. The findings of Nyasulu et al. [10] are similar to those of the present study, where ceftriaxone had a mean resistance of $66 \%$ and ceftazidime $82 \%$.

In this study the average resistance to imipinem was $32.9 \%$, which is very high when compared with $0.0 \%$ found by Van der Meeren et al. [11], 1.9\% found by Monteiro et al. [8] and $9 \%$ by Nyasulu et al. [10]. In a similar study, Sambyal et al. [12], found a mean resistance to imipenem of $44.3 \%$, a value very close to the findings in the present study.

Gentamicin was the second antibiotic most tested against bacteria isolated in the ICU, having an average resistance of $70.3 \%$, a result similar to $83.9 \%$ found by Van der Meeren et al. [11], but different from those found by Monteiro et al. [8] and Nyasuluet et al. [10] in which they obtained percentages of $52 \%$ and $52.3 \%$ respectively.

Ciprofloxacin was the antibiotic most tested against strains of bacteria isolated in the ICU, having an average resistance of $65.6 \%$, a very high result when compared to Monteiro et al. [8] and Van der Meeren et al. [11] where they obtained percentages of $16.5 \%$ and $35.5 \%$ respectively.

Vancomycin is specifically used in the treatment of Gram-positive bacilli and, in this study had an average resistance of $20 \%$. These findings are similar to those of Nhantumbo et al. [13] where it obtained resistance with a percentage of $11.8 \%$.

The mean macrolide resistance was $63.4 \%$, being azithromycin (100\%) and erythromycin (61.5\%). Nhantumbo et al. [13] obtained an average resistance of $23.5 \%$ to erythromycin, a very low value when compared to the findings in the present study, but similar to the $34.5 \%$ obtained by Nyasulu et al. [10]. Huband et al. [14] in Gram-positive bacteria isolates in the United States of America, obtained a mean resistance ranging from $44.1 \%$ to $89.2 \%$.

Nyasulu et al. [10], obtained an average resistance of $32.4 \%$ to clindamycin, a result very close to the $36.1 \%$ found in the present study. Nhantumbo et al. [13] found a sensitivity to clindamycin of $100 \%$.

Doxycycline was only tested in Adults ICU on Gram-negative bacteria, presenting a resistance of $100 \%$. These findings are significantly different from the results of Zhang et al. [15] and Van der Meeren et al. [11] in which they obtained a resistance to doxycycline with percentage of $70.1 \%$ and $58.1 \%$ respectively.

In the present study resistance to co-trimoxazole was $82.4 \%$, and was frequently tested in the pediatrics ICU. The results of the present study are similar to those found by Van der Meeren et al. [11], where it obtained a resistance of $71 \%$ to co-trimoxazole. Nyasulu et al. [10] obtained an average resistance of $58.1 \%$, which very low value when compared to the findings in the present study.

In this study, the resistance of strains isolated from bacteria to chloramphenicol was $52.4 \%$, which is very low when compared with 93.5\% obtained by Van der Meeren et al. [11]. Monteiro et al. [8] found an average resistance of $39.1 \%$ to nitrofurantoin a value that is higher than $25 \%$ of the present study.
The bacteria isolated in the HCM ICUs presented an average resistance of $62.4 \%$, being slightly higher in pediatric patients.

\section{Conclusions}

In this study, it was verified that the EMNL antibiotics present high resistance rates against tested bacteria, with higher Gram-negative percentages. There is a need for EMNL to be updated with the introduction of new drugs considered as last resort options and used only under the most severe circumstances when all alternatives failed. With the development of new antibiotics at a slow pace, regular monitoring of infections and resistance profiles, rational use of antibiotics and standardized measures of infection control can have a major impact on reducing high resistance rates.

\section{References}

1. Ramya K, Sankar P (2018) Antimicrobial resistance区: Alarming universal concern. Clin Pharmacol Transl Med 2: 87-88.

2. Centers for Disease Control and Prevention (2013) Antibiotic resistance threats in the United States. Atlanta.

3. World Health Organization (2017) The selection and use of essential medicines. WHO Expert Comm 20: 1-13.

4. World Health Organization (2015) Global action plan on antimicrobial resistance. (1st edn) Geneva, Switzerland.

5. MISAU. Lista Nacional de Medicamentos Essenciais. 1a Edição. (Departamento Farmacêutico). Maputo; 2017.

6. World Health Organization (2017) The growing threat of antimicrobial resistance. Geneva, Switzerland pp: 1-16.

7. Mahaluça FA, Sacarlal J, Essack S (2018) The etiology of hospital infections in the intensive care unit of a reference hospital in Southern Mozambique. Clin Microbiol 7: 1-5.

8. Monteiro LGS, Zimba TF, Sidat M (2015) Sensitivity of Enterobacteriaceae isolates from Maputo Central Hospital, Mozambique 2009-2010. Rev Cient UEM Sér Ciênc Bioméd Saúde Pública 1: 7-13.

9. Vandepitte J, Engback K, Piot P, Iteuk C (2003) Basic laboratory procedures in clinical bacteriology. (2nd edn) Geneva, Switzerland.

10. Nyasulu PS, Murray J, Perovic O, Koornhof H (2017) Laboratory information system for reporting antimicrobial resistant isolates from academic hospitals, South Africa. J Infect Dev Ctries 11: 705-718.

11. Van der Meeren BT, Millard PS, Scacchetti M (2014) Emergence of methicillin resistance and Panton-Valentine leukocidin positivity in hospital and community acquired Staphylococcus aureus infections in Beira, Mozambique. Trop Med Int Heal 19: 169-176.

12. Sambyal SS, Kaur A, Soodan PS, Mahajan B, Sambyal SS, et al. (2015) Changing antibiotic sensitivity pattern in gram negative nonfermenting isolates: A study in a tertiary care hospital. J Dent Med Sci 14: 129-133.

13. Nhantumbo AA, Cantarelli VV, Caireão J (2015) Frequency of pathogenic paediatric bacterial meningitis in Mozambique: The critical role of multiplex real-time polymerase chain reaction to estimate the burden of disease. PLoS One 10: 1-17.

14. Huband M, Pfaller M, Sader H, Flamm R (2017) In vitro activity of omadacycline and comparator compounds against gram-positive isolates collected in the us during 2016 as part of a global surveillance program. Open Forum Infect Dis 4: S374.

15. Zhang T, Wang CG, Lv JC, Wang RS, Zhong XH (2018) Survey on tetracycline resistance and antibiotic-resistant genotype of avian Escherichia coli in North China. Poult Sci 91: 2774-2777. 